\title{
SUSTENTANDO O CÉU: UMA RESENHA DAS PALAVRAS DE UM XAMÃ YANOMAMI
}

\author{
MARCUS ANTONIO SCHIFINO WITTMANN ${ }^{1}$
}

UFRGS

\section{RESENHA}

KOPENAWA, Davi; ALBERT, Bruce. A queda do céu: palavras de um xamã Yanomami. São Paulo: Companhia das Letras, 2015. 730 p.

Ao acabar a leitura do livro $A$ queda do céu, de Davi Kopenawa e Bruce Albert, duas perguntas ficaram rondando minha mente: "como fazer antropologia depois disso?" e "o que nós, os brancos, o povo da mercadoria, vamos fazer para que o céu não caia?". Acredito que as pistas para respondê-las estão espalhadas, escondidas e, ao mesmo tempo, saltando aos olhos na fala de Davi Kopenawa. O caminho é longo e a viagem profunda.

É muito provável que a maioria das pessoas que entram em contato com esse livro já tenha escutado ou lido algo sobre ele anteriormente. Pelo menos nos círculos científicos da etnologia indígena brasileira, o nome "a queda do céu" já era citado quando se conversava sobre os novos rumos da etnografia e a importância dessa obra, mesmo antes de ela ser editada na língua portuguesa. O público brasileiro que não tinha acesso ao original em francês, publicado em 2010, ou à

\footnotetext{
${ }^{1}$ Mestrando em Antropologia Social pela Universidade Federal do Rio Grande do Sul e estudante associado do Núcleo de Antropologia das Sociedades Indígenas e Tradicionais (NIT) da mesma Universidade. E-mail: wittmann.marcus@gmail.com .
} 
versão inglesa, publicada três anos depois, já podia começar a sentir o que estava por vir através de trabalhos de Albert e Kopenawa². Mesmo assim, não havia como se preparar para tudo que a tradução portuguesa do livro estava trazendo consigo. Provavelmente ainda serão necessários alguns anos para se digerir $A$ queda do céu, seja por sua importância antropológica, literária, política, social ou cultural. Tentaremos aqui traçar alguns pontos de reflexão sobre esse livro, nos focando mais no tema do discurso de Kopenawa acerca dos não indígenas 3 .

$A$ queda do céu é um livro único. Embora algumas obras também tenham uma força literária parecida no que tange à narrativa do contato entre brancos e indígenas, como a de Pozzobon (2013), e outras tragam líderes indígenas falando por si próprios, o compêndio de entrevistas de Ailton Krenak (2015), por exemplo; o trabalho de Kopenawa e Albert é diferente de todas essas.

$A$ queda do céu é fruto não apenas de uma intensa e extensa pesquisa e estudo de um antropólogo junto a uma comunidade indígena yanomami, mas retira suas forças muito mais da relação de amizade entre Bruce Albert e Davi Kopenawa. Amizade essa que não se limita às barreiras de um convívio na Terra Indígena Yanomami, na fronteira entre Brasil e Venezuela, durante as visitas de Albert, mas extrapola para a atuação política, para o ativismo ambiental, para viagens ao redor do mundo e para trabalhos acadêmicos. Bruce e Davi se conhecem há quarenta anos, quando das primeiras pesquisas do antropólogo nas terras yanomami e quando Davi trabalhava para a Funai, sendo categorizado por muitos como um "índio aculturado". Nos mais de trinta anos desde que foi estabelecida uma relação de amizade entre os dois, Bruce Albert se transformou em um dos mais respeitados antropólogos e ativista político referente às questões yanomami e Davi Kopenawa, um dos maiores xamãs e líderes indígenas atuais. O livro surgiu através de um pacto político, antropológico, literário e de alteridade entre os dois autores, do qual surgiu um "texto escrito/falado a dois", no qual o autor das palavras transcritas e o autor da redação empenharam-se em ser um só (KOPENAWA e ALBERT, 2015, p. 537).

\footnotetext{
${ }^{2}$ Ver Albert e Kopenawa (1999) e Albert (2002).

${ }^{3}$ Uma ótima resenha do livro, mais voltada para uma análise da cosmologia yanomami, é o texto de Kelli Luciani, Kopenawa e Albert (2013).
} 
É desse contexto, ainda raro no campo antropológico, que nasce A queda do céu. O texto foi construído a partir de mais de noventa e três horas de entrevistas na língua yanomami entre os autores, as quais foram traduzidas para o francês por Albert em mais de mil páginas, para só depois serem editadas, selecionadas, recortadas e formatadas por ambos. Essas conversas foram gravadas entre 1989 e o início dos anos 2000, em diferentes lugares e situações - desde encontros na Terra Indígena Yanomami até corredores de ministérios em cidades brasileiras. As falas de Davi, junto com alguns de seus desenhos, foram espalhadas em 440 páginas de texto, sem separação ou indicação do momento da gravação, e também sem "interrupções antropológicas". As notas explicativas de Bruce Albert, mais de mil, encontram-se ao final do livro, deixando que as palavras de Davi corram livremente. Inclusive é possível ler o livro sem recorrer às notas de Albert, embora talvez para alguns termos e situações narradas elas sejam muito úteis. Somado a isso temos quatro anexos escritos por Bruce Albert sobre diferentes aspectos referentes aos Yanomami, mapas da região, um glossário etnobiológico e um geográfico, trinta e duas páginas com fotos de diferentes fases da vida de Davi e um prefácio assinado por Eduardo Viveiros de Castro. Todas essas partes adicionam a um entendimento mais aprofundado sobre o povo Yanomami, sua história, cosmologia e língua, mas não são imprescindíveis à leitura do livro. As palavras de Davi Kopenawa se sustentam, tanto na questão literária quanto cosmológica e antropológica, por si mesmas.

As únicas divisões no que, no geral, é um relato fluido são os vinte e quatro capítulos separados em três partes distintas. Na primeira seção, "Devir Outro", temos os relatos mais voltados à iniciação xamânica de Davi Kopenawa e às bases da cosmologia yanomami e seus espíritos xapirit; na seção seguinte, "A Fumaça do Metal", Davi conta mais sobre sua vida entre a terra indígena e a cidade, e a invasão dos garimpeiros à procura de ouro; já na última parte do livro, "A queda do céu", lemos as impressões de Davi acerca de suas viagens ao exterior e sobre as causas da morte dos xamãs, a destruição da floresta e a

\footnotetext{
${ }^{4}$ Os xapiri, um tipo de espírito guia para os xamãs yanomami, são personagens centrais na narrativa de Kopenawa, a qual traz descrições muito detalhadas de seus corpos, adornos, ações e danças. Um relato visual das viagens xamânica pode ser visto no filme Xapiri (2012).
} 
consequente queda do céu. Embora exista essa grande divisão temática, em praticamente todos os capítulos são tratados os assuntos de xamanismo, destruição da natureza, a vida de Davi e suas impressões sobre os brancos.

A queda do céu não é apenas um livro "sobre" os Yanomami, ele é um livro "para" nós, o povo da mercadoria. Este é o nome que Davi usa para caracterizar os não indígenas, os quais, embora também tenham sido criados por Omama, o demiurgo yanomami, possuem algumas diferenças. Os brancos se distinguem por seus corpos, pálidos e não pintados, e por seu pensamento e língua, esfumaçados e confusos. Kopenawa é enfático ao explicar a natureza desse desvio na obra de Omama: o que fez isso com os brancos foi o capitalismo, esse feroz, selvagem e canibal capitalismo que nos transformou no povo da mercadoria. E o produto dessa ganância, com suas máquinas e indústrias, é a fumaça do metal, a epidemia xawara, que impregna o mundo inteiro e mata todos os seres que o habitam.

\begin{abstract}
[...] as orelhas dos brancos não escutam as palavras dos espíritos! Eles só prestam atenção no seu próprio discurso e nunca se dão conta de que é a mesma fumaça de epidemia que envenena e devora suas próprias crianças. Seus grandes homens continuam mandando os genros e os filhos arrancarem da escuridão da terra as coisas maléficas que alastram as doenças de que sofremos todos. Assim, o sopro da fumaça dos minérios queimados se espalha por toda parte. $O$ que os brancos chamam de o mundo inteiro fica corrompido pelas fábricas que produzem todas as suas mercadorias, suas máquinas e seus motores. [...] Com a fumaça dos minérios, do petróleo, das bombas e das coisas atômicas, os brancos vão fazer adoecer a terra e o céu. Então, os ventos e tempestades acabarão entrando em estado de fantasma. No final, inclusive os xapiri e a imagem de Omama serão atingidos! (KOPENAWA e ALBERT, 2015, p. 370).
\end{abstract}

As palavras de Davi Kopenawa acerca desse assunto são o exemplo máximo da antropologia reversa de Roy Wagner (2012), mostrando o que os outros pensam, interpretam e teorizam sobre nós. $A$ queda do ceú é um manifesto indígena sobre como os brancos estão destruindo a natureza e como isso deve mudar; é um documento 
diplomático (VIVEIROS DE CASTRO, 2015, p. 39) esperando a assinatura de uma das partes; é um "bíblia xamânica" (VIENNE, 2014) mostrando o caminho para a salvação de todos nós.

$A$ queda do céu é um grande livro em diferentes aspectos. Com suas 730 páginas e pesando quase um quilo, é uma obra que possui algumas dificuldades de manuseio. Além de extensa e pesada, as notas explicativas de Bruce Albert ao texto de Davi Kopenawa, como já citado, se encontram no final do livro. Tal fato causa alguns problemas, tanto no que tange à leitura corrida do texto, quanto à manipulação do livro, obrigando o leitor a manejar diversas páginas para chegar às notas. Além de grande, $A$ queda do céu é altiva. Sua capa ilustrada com o perfil de um jovem yanomami tem apenas duas cores: o preto e o vermelho, o jenipapo e o urucum. Todavia, não podemos deixar de citar que toda essa materialidade, além da diagramação, das imagens coloridas, entre outras questões, tem como consequência um preço relativamente alto para se adquirir o livro. Embora a obra seja, em seu âmago, uma crítica xamânica ao povo da mercadoria, ela é uma mercadoria. Contudo, isso não retira nada do seu poder narrativo, inclusive insere uma pitada de ironia.

Em tempos de retrocessos da política indigenista e ambiental no Brasil - a PEC 215, o novo código florestal e de mineração, a bancada ruralista no Congresso, o crime da Samarco em Mariana (MG), a contaminação do povo Yanomami por mercúrio e o Brasil sendo o líder do ranking de morte de ambientalistas - as palavras de Davi são mais do que necessárias.

Os brancos não pensam muito adiante no futuro. Sempre estão preocupados demais com as coisas do momento. É por isso que eu gostaria que eles ouvissem minhas palavras através dos desenhos que vocês fez delas; para que penetrem em suas mentes. Gostaria que, após tê-las compreendido, dissessem a si mesmo: "Os Yanomami são gente diferente de nós, e no entanto suas palavras são retas e claras. Agora entendemos o que eles pensam. São palavras verdadeiras! A floresta deles é bela e silenciosa. Eles ali foram criados e vivem sem preocupação desde o primeiro tempo. 0 pensamento deles segue caminhos outros que o da mercadoria. Eles querem viver como Ihes apraz. Seu costume é diferente. Não têm peles de imagens, mas 
conhecem os espíritos xapiri e seus cantos. Querem defender sua terra porque desejam continuar vivendo nela como antigamente. Assim seja!". (KOPENAWA e ALBERT, 2015, p. 64-65).

A mata deu seu recado. É chegada a nossa hora de aceitarmos o pacto com ela antes que o céu caia sobre todos nós.

\section{Referências bibliográficas}

ALBERT, Bruce. O ouro canibal e a queda do céu: uma crítica xamânica da economia política da natureza (Yanomami). In: ALBERT, Bruce; RAMOS, Alcida Rita (Org.). Pacificando o branco: cosmologias do contato norte-amazônico. São Paulo: UNESP, 2002. p. 239-276.

KELLI LUCIANI, José Antonio; KOPENAWA, Davi; ALBERT, Bruce. La chute du ciel: paroles d'um chaman yanomami. Revista de Antropologia da UFSCar, São Carlos, v. 5, n. 1, p. 172-187. jan./jun. 2013.

KOPENAWA, Davi; ALBERT, Bruce. Descobrindo os brancos. In: NOVAES, Adauto (Org.). A Outra margem do Ocidente. São Paulo: Companhia das Letras, 1999. p. 1521.

Letras, 2015.

A queda do céu: palavras de um xamã Yanomami. São Paulo: Companhia das

KRENAK, Ailton; COHN, Sérgio (Org.). Ailton Krenak: Encontros. Rio de Janeiro: Azougue, 2015.

POZZOBON, Jorge. "Vocês, brancos, não têm alma": histórias de fronteira. Rio de Janeiro: Beco de Azougue, 2013.

VIENNE, Emmanuel. A shamanic Bible and its enunciation. Hau: Journal of Ethnographic Theory, v. 4, n. 2, p. 311-317, 2014.

VIVEIROS DE CASTRO, Eduardo. Prefácio: o recado da mata. In: KOPENAWA, Davi; ALBERT, Bruce. A queda do céu: palavras de um xamã Yanomami. São Paulo: Companhia das Letras, 2015. p. 11-41.

WAGNER, Roy. A Invenção da Cultura. São Paulo: Cosac Naify, 2012.

XAPIRI. Direção: Stella Senra, Bruce Albert, Gisela motta, Laymert Garcia dos Santos, Leando Lima. Produção: Cinemateca Brasileira, Instituto Socioambiental. 2012, $54 \mathrm{~min}$. 
Recebido em: 18/11/2016 * Aprovado em: 22/09/2016 * Publicado em: 18/12/2016 